\title{
Solar Radiation Gridded Satellite data comparison in Gran Canaria Island
}

\author{
L. Mazorra Aguiar ${ }^{1}$, J. Polo ${ }^{2}$, F. Díaz ${ }^{1}$ and J.M. Vindel ${ }^{3}$ \\ ${ }^{1}$ Institute for Intelligent Systems and Numerical Applications in Engineering, University of Las Palmas de Gran Canaria, \\ 35017 Las Palmas de Gran Canaria (Spain) \\ Phone/Fax number: +0034 928 451989, e-mail: luis.mazorra@ulpgc.es, felipe.diaz@ulpgc.es \\ ${ }^{2}$ Photovoltaic Solar Energy Unit, Renewable Energy Division (Energy Dep) of C.I.E.M.A.T. \\ ${ }^{3}$ Renewable Energy Division (Energy Dep) of C.I.E.M.A.T. \\ Avda Computense 40, 28040 Madrid, Spain \\ email: jesus.polo@,ciemat.es, JoseMaria.Vindel@ciemat.es
}

\begin{abstract}
During the last years solar energy has been increasing the percentage of the total energy production around the world and it is expected it persists growing notably [1]. In insular grids, such as Canary Islands, the knowledge of solar radiation behaviour is one of the most important variables in order to ensure the stability for power systems. In this paper we study the suitability of Gridded Satellite data for modelling solar radiation for both PV and CSP purposes. The analysis and comparison is performed using hourly Global and Direct Solar radiation from the satellite model CM SAF database and four ground measurement stations in Gran Canaria. This study could give us a better knowledge of solar radiation behavior in a wide spatial and temporal coverage. Moreover, an accurate satellite radiation data could improve solar radiation forecasting for power systems manage systems [2].
\end{abstract}

\section{Key words}

Global Solar Radiation, Satellite data monitoring, CMSAF, SIAR.

\section{Introduction}

Satellite derived data provide a grate spatial and temporary resolution for different regions around the world. Geostationary meteorological satellites estimates different variables from atmosphere images. This information could be used to evaluate the evolution of solar radiation for the surroundings at a desire location. Satellite information about cloud variability have been used to improve few hours ahead forecasting using cloud motion vectors [3, 4]. In recent years, some works described also the improving of solar radiation hourly forecasting using satellite derived data as inputs in different statistical models $[5,6,7,8]$.

Depending on the geographical area, satellite models estimate solar radiation data with different spatial and temporary resolution. At BSRN stations around the world, hourly errors between ground and satellite data provide values around $17 \backslash \%$ for global and $34 \backslash \%$ for direct normal irradiance [9]. Moreover, using satellite-derived data obtained with hourly Helioclim3 database, Eissa reports errors between $17 \backslash \%$ and $30 \backslash \%$ for different stations in Egypt [10] and Mazorra show errors with an average $12.21 \% \mathrm{rRMSE}$ for a southern station and $27.8 \backslash \% \mathrm{rRMSE}$ for a northern station in Gran Canaria island [7]. Data obtained from CMSAF database report around $4 \backslash \%$ rRMSE for a set of station in Spain with yearly GHI [11].

This work is divided into the following parts: the first section makes an introduction of the Gran Canaria measurement station and the datasets available for the study. The second section provides a brief description of a gridded satellite data used during the study and analyze the suitability of these data at the region of study, both with global and direct solar radiation. Finally, the results obtained during the comparison between satellite and ground data are shown in last section.

\section{Solar radiation data}

Satellite-derived data are very useful for a better knowledge of solar radiation in a wide coverage. However, Satellite models need to be validated using ground stations around the spatial coverage with a high quality measurement. Ground data used in this survey were obtained in six measurement stations in Gran Canaria Island, Gáldar (lat: 28.1559, long: -15.6652, alt: 16), San Mateo (lat: 28.0194, long: -15.5330, alt: 785) and Sta. Lucía Vecindario (lat: 27.8422, long: -15.4303, alt: 76) handled by the Agroclimatic Information System for Irrigation (SIAR) and Maspalomas (lat: 27.7716, long: 15.5841, alt: 265) handled by State Meteorological Agency (AEMET), the only station with DNI data. The raw data obtained for this work includes the years 2010 and 2011 .

To avoid wrong measurements during the study it is a common practice to use a quality check procedure. In this 
case the raw data for two years were filtered out using physically possible limits. Indeed, all Global solar radiation over exoatmospheric theoretical radiation or below zero are considered not valid data. Exoatmospheric radiation is calculated using the solar constant and various solar angles modified according to the time of year. On the other hand, night values are not considered to calculate errors and deviation between satellite and ground data. The zenith angle is the variable used to distinguish between night, over $80^{\circ} \mathrm{C}$, and daily data. Once datasets were filtered the final number of hourly data are 7285 for Maspalomas, 7250 for Gáldar, 7250 for San Mateo and 7267 for Vecindario.

\section{Gridded Satellite data}

Satellite-derived data used in this work was obtained from the Satellite Application Facility on Climate Monitoring (CM SAF). Images taken from Meteosat Second Generation (MSG) geostationary satellite network with SEVIRI sensor on board and NOAA polar satellites with AVHRR sensor has been processed to obtain all CMSAF information [12]. The method used to covert satellite information and images in global and direct normal irradiance is Heliosat method and MAGIC approach. The radiation data estimated with this method are validated with BSRN ground stations and provided in SARAH-E database $[13,14]$. The selected area contains the entire Canary Islands as well as a significant portion. This area is defined, in decimal degrees, by the coordinates latitude $[+27.0000$ to $+30.0000]$, and longitude [-19.0000 to -13.0000$]$, where each pixel possesses a spatial resolution of $0.5 \times 0.5^{\circ}$.

\section{A. Surface Incoming Solar Radiation (SIS)}

To study the Global Solar Radiation we retrieved shortwave incoming solar radiation (SIS) from CM SAF database. SIS, expressed in $\mathrm{Wm}-2$, is the irradiance reaching a horizontal plane at the Earth surface in the 0.2 $4 \mu \mathrm{m}$ wavelength region. CM SAF provided hourly data for the whole grid for years 2010 and 2011. Daily average are calculated following CM SAF recommendations [14], $S I S_{D A}=S I S_{C L S D A} \frac{\sum_{i=1}^{n} S I S_{i}}{\sum_{i=1}^{n} S I S_{C L S i}}$. The monthly average is calculated from the daily means. The results of CM SAF database are quite satisfactory for the whole Canary Islands region as it is easily observed in Fig. 1 for monthly means in July and October only for Gran Canaria. Gridded satellite data represent major presence of clouds in northern areas of the island during summer months. However, even if the in October the presence of cloudy days is less than in summer, the radiation levels higher during the summer. The major presence of Trade Winds during the summer and the complex orography of the northern parts of the Island generate an accumulation of clouds. In this case, the analysis of satellite data give us consistence information according to climatological knowledge and ground measurement data.
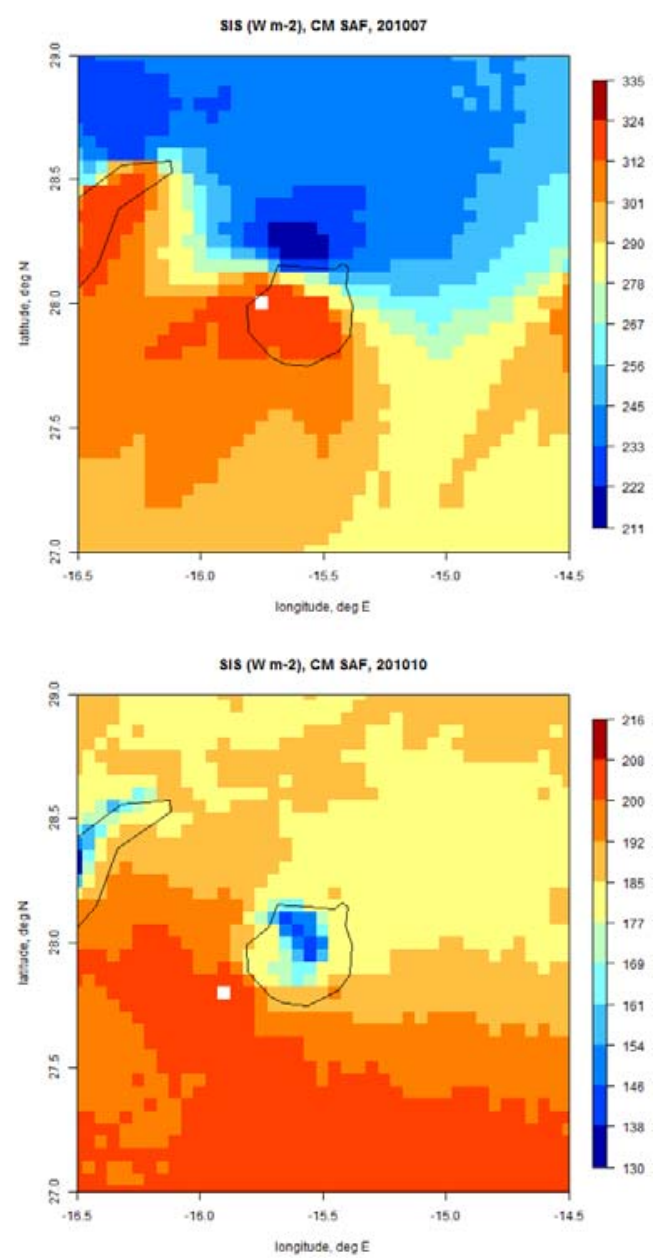

Fig. 1 SIS Monthly means of gridded satellite data for Gran Canaria Island, July (up) and October (down) 2010.

\section{B. Direct normal irradiance (DNI)}

To study the Direct Solar Radiation we retrieved direct normal irradiance (DNI) from CM SAF database. DNI, expressed in $\mathrm{Wm}-2$, is the irradiance at the surface normal to the direction of the sun in the $0.2-4 \mu \mathrm{m}$ wavelength region. As in case of SIS, we retrieved hourly data an calculated daily average following $\mathrm{CM}$ SAF recommendation, $D N I_{D A}=\frac{\sum_{i=1}^{n} D N I_{i}}{n}$. As observed in Fig. 1 for SIS data, DNI monthly means represent climate general conditions in Canary Islands region, Fig. 2. In this figure, for summer months (up) it is easily observed the high presence of clouds in northern areas. While during winter months (down) there are more number of completely clear sky days in whole island, not only in south areas. Anyway, the solar radiation values are lower in winter months even with clear sky days. 

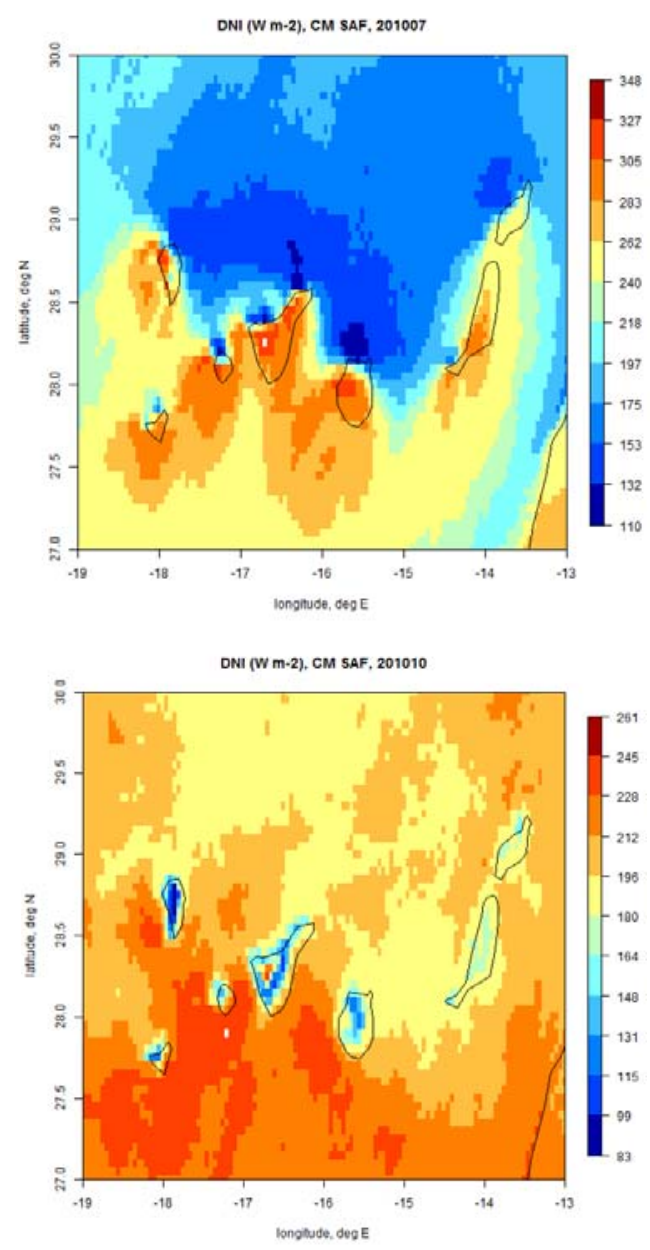

Fig. 2 DNI Monthly means of gridded satellite data for Canary Islands, July (up) and October (down) 2010.

\section{Data Comparison and conclusions}

The achieved accuracy for SIS and DNI is based on the comparison with ground measurement stations. Overall, the relative root mean square error for DNI is larger than obtained for SIS data for hourly data and Satellite-derived data normally overestimate ground radiation data. However, both data are quite satisfactory for daily and monthly errors.

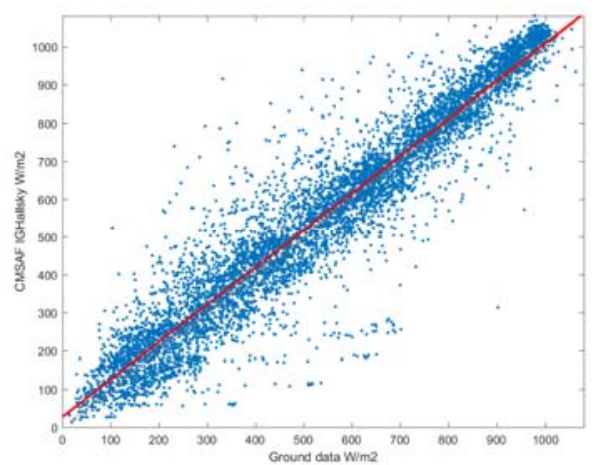

Fig. 3 SIS hourly data comparison of satellite and ground data for Vecindario using all filtered out days.
For Global radiation (SIS) we obtained errors from 15\% rRMSE to $31 \%$ rRMSE and from $13 \%$ rMAE to $26 \%$ rMAE. Southern stations with more presence of clear sky days obtained better results for both rRMSE and rMAE. While the worst results are registered in San Mateo station, situated in northern area and at $785 \mathrm{~m}$. high. Fig. 3 represent the satellite data and ground measurement hourly data for Vecindario station using all solar radiation filtered out data. CMSAF obtained very good accuracy results comparing the linear regression line.

In this study, we also calculated and analyzed the accuracy of satellite data separating clear sky days and days with a presence of cloud hours. Only using completely clear sky days, the obtained results become much better than using all days, with error between $8 \%$ and $14 \%$ in terms of rRMSE depending on the station and between $6 \%$ and $9 \%$ in terms of rMAE. In Fig. 4 , it is easily observable that for clear sky days the obtained results fit linear regression ground measured data, while for cloudy days this linear regression shows a deviation from measured data.
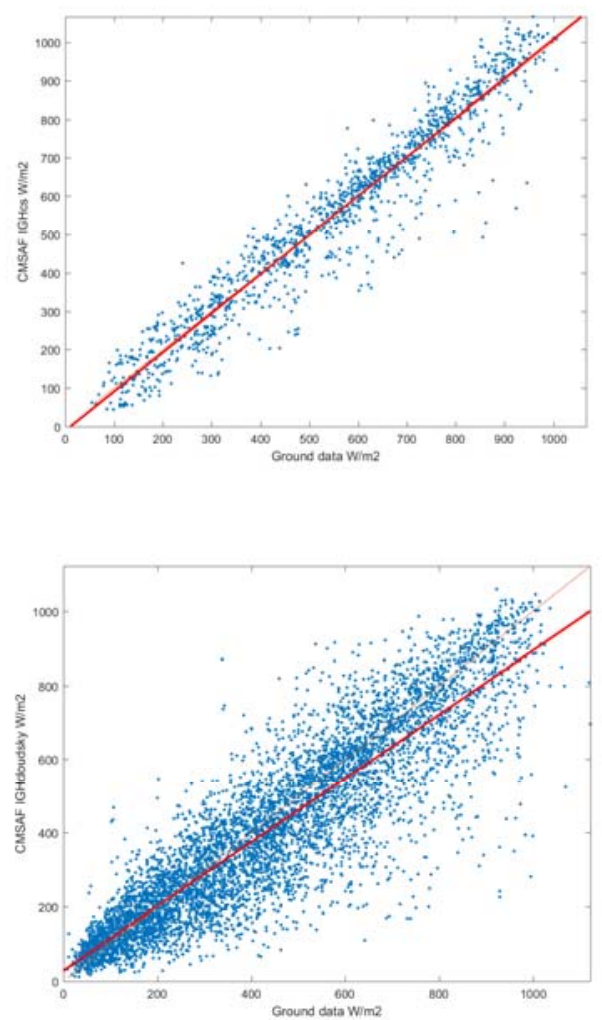

Fig. 4 SIS hourly data comparison of satellite and ground data for Gáldar station, using clear days (up) and cloudy days (down).

Fig. 5 shows the average residuals between satellite and ground data calculated by months for one southern station (Vecindario) and one northern station (Gáldar). It is not observable a monthly trend to establish a certain behavior depending on the month of the year. However, in southern stations the dispersion of data during summer months 
present a lower range than observed for the same months in Northern stations.

On the other hand, Direct Normal radiation (DNI) results obtained for Maspalomas stations present a higher errors comparing with SIS data. With all sky days, DNI estimated errors present values around 25\% rRMSE and 34\% rMAE, while SIS errors show values around 23\% rRMSE and 19\% rMAE for the same station.
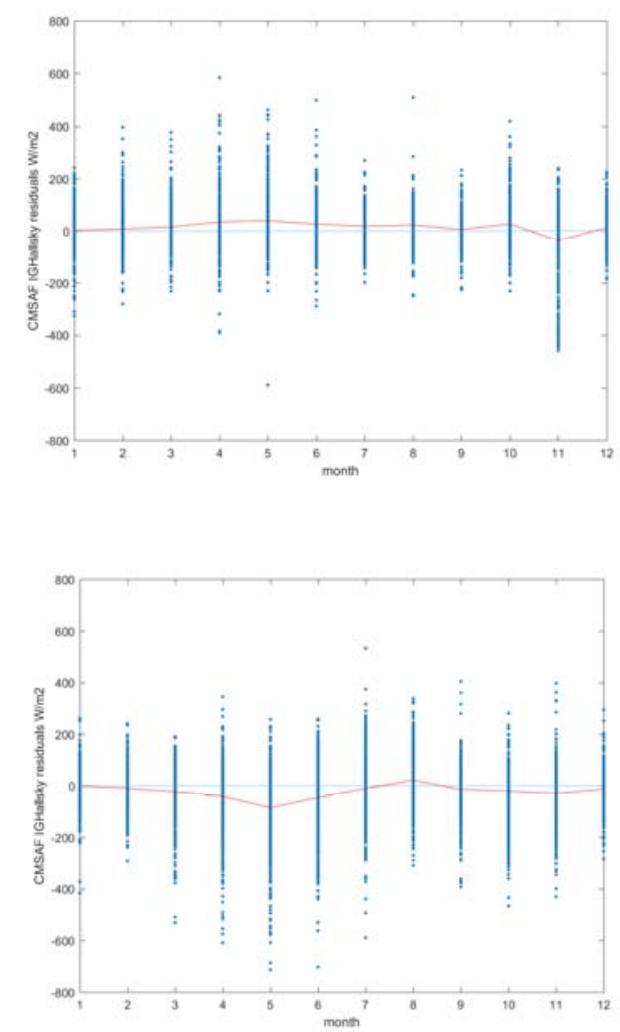

Fig. 5 SIS residuals between satellite and ground data for all hourly data, Vecindario (up) and Gáldar (down) stations.

\section{References}

[1] U.S. Energy Information Administration,, "Annual Energy Outlook 2017,” 2017. [Online]. Available: http://eia.gov//aeo.

[2] M. Wittmann, H. Breitkreuz, M. Schroedter-Homscheidt y M. Eck, «Case studies on the use of solar irradiance forecast for optimized operation strategies of solar thermal power plants,» Selected Topics in Applied Earth Observations and Remote Sensing IEEE Journal, vol. 1, $\mathrm{n}^{\mathrm{o}}$ 1, pp. 18-27, 2004.

[3] R. Perez, S. Kivalov, J. Schlemmer, K. Hemker Jr, D. Renné and T. Hoff, "Validation of short and medium therm operational solar radiation forecasts in the US," Solar Energy, vol. 84, pp. 2161-2172, 2010.

[4] A. Hammer, D. Heinemann, E. Lorenz y B. Lückehe, «Short-term forecastingof solar radiation: a statistical approach using satellite data.,» Solar Energy, vol. 67, $\mathrm{n}^{\mathrm{o}}$ 1, pp. 139-150, 1999.

[5] R. Dambreville, P. Blanc, J. Chnussot and D. Boldo, "Very short term forecasting of the Global Horizontal
Irradiance using a spatio-temporal autoregresive model," Renewable Energy, vol. 72, pp. 291-300, 2014.

[6] R. Marquez, H. Pedro and C. Coimbra, "Hybrid solar forecasting method uses satellite imaging and ground telemetry as inputs to ANNs," Solar Energy, vol. 92, pp. 176-188, 2013.

[7] L. Mazorra Aguiar, B. Pereira, M. David, F. Diaz y P. Lauret, «Use of satellite data to improve solar radiation forecasting with Bayesian Artificial Neural Networks,» Solar Energy, vol. 122, pp. 1309-1324, 2015.

[8] A. Zagouras, H. Pedro and C. Coimbra, "On the role of lagged exogenous variables and spatio-temporal correlations in improving the accuracy of solar forecasting methods," Renewable Energy, vol. 78, pp. 203-2018, 2015.

[9] P. Ineichen, «Long term satellite global, beam and diffuse irradiance validation,» Energy Procedia, vol. 48, pp. 1586-1596, 2014.

[10] Y. Eissa, M. Korany, Y. Aoun, M. Boraiy, W. Abdel, M. Magdy, S. Alfaro, P. Blanc, M. El-Metwally, H. Ghedira $y$ K. Hungershoefer, «Validation of the surface downwelling solar irradiance estimates of the HelioClim3 database in Egypt,» Remote Sensing, vol. 7, no 7, pp. 9269-9291, 2015.

[11] F. Antonanzas-Torres, A. Sanz-García, F. J. Martínez de Pisón y Ó. Perpiñán-Lamigueiro, «Evaluation and improvement of empirical models of global solar irradiation: Case study northern Spain,» Renewable energy, vol. 60, pp. 604-614, 2013.

[12] J. Schulz, P. Albert, H.-D. Behr, D. Caprion, H. Deneke y S. Dewitte, «Operational climate monitoring from space: the Eumetsat Satellite Application Facility on Climate Monitoring (CM-SAF),» Atmospheric Chemistry and Physics, vol. 9, pp. 1687-1709, 2009.

[13] CM SAF Technical Team, «Climate monitoring SAF annual validation report,» Technical Report CM SAF, 2008.

[14] J. Trentmannn, «Meteosat-East Solar Surface Irradiance Data Records,» EUMETSAT Satellite Application Facility on Climate Monitoring, 2016. 